\title{
Changes in physical activity and all-cause mortality in COPD
}

\author{
Anouk W. Vaes ${ }^{1,2}$, Judith Garcia-Aymerich ${ }^{3,4,5}$, Jacob L. Marott ${ }^{6}$, Marta Benet ${ }^{3}$, \\ Miriam T.J. Groenen ${ }^{1}$, Peter Schnohr ${ }^{6}$, Frits M.E. Franssen ${ }^{1}$, Jørgen Vestbo ${ }^{7,8}$, \\ Emiel F.M. Wouters ${ }^{1,9}$, Peter Lange $e^{6,10,11,13}$ and Martijn A. Spruit ${ }^{1,12,13}$
}

\begin{abstract}
Affiliations: 'Dept of Research and Education, CIRO+, Horn, The Netherlands. ${ }^{2}$ Dept of Physiotherapy, CIRO+, Horn, The Netherlands. ${ }^{3}$ Center for Research in Environmental Epidemiology (CREAL), Barcelona, Spain. ${ }^{4}$ CIBER Epidemiologia y Salud Publica (CIBERESP), Barcelona, Spain. ${ }^{5}$ Departament de Ciències Experimentals i de la Salut, Universitat Pompeu Fabra (UPF), Barcelona, Spain. ${ }^{6}$ Copenhagen City Heart Study, Frederiksberg Hospital, Copenhagen, Denmark. ${ }^{7}$ Dept of Respiratory Medicine, Odense University Hospital, Odense, Denmark. ${ }^{8}$ Respiratory and Allergy Research Group, Manchester Academic Health Science Centre, University of Manchester, Manchester, UK. ${ }^{9}$ Dept of Respiratory Medicine, MUMC+, Maastricht, The Netherlands. ${ }^{10}$ Dept of Cardiology and Respiratory Medicine, Copenhagen University Hospital Hvidovre, Hvidovre, Denmark. ${ }^{11}$ Dept of Public Health, University of Copenhagen, Copenhagen, Denmark. ${ }^{12}$ REVAL Rehabilitation Research Center, BIOMED - Biomedical Research Institute, Faculty of Medicine and Life Sciences, Hasselt University, Diepenbeek, Belgium. ${ }^{13}$ Joint senior authors.
\end{abstract}

Correspondence: Anouk W. Vaes, CIRO+, Program Development Centre, Hornerheide 1, 6085 NM Horn, The Netherlands. E-mail: AnoukvaesQciro-horn.nl

ABSTRACT Little is known about changes in physical activity in subjects with chronic obstructive pulmonary disease (COPD) and its impact on mortality. Therefore, we aimed to study changes in physical activity in subjects with and without COPD and the impact of physical activity on mortality risk.

Subjects from the Copenhagen City Heart Study with at least two consecutive examinations were selected. Each examination included a self-administered questionnaire and clinical examination.

$1270 \mathrm{COPD}$ subjects and 8734 subjects without COPD (forced expiratory volume in $1 \mathrm{~s} 67 \pm 18$ and $91 \pm 15 \%$ predicted, respectively) were included. COPD subjects with moderate or high baseline physical activity who reported low physical activity level at follow-up had the highest hazard ratios of mortality (1.73 and 2.35, respectively; both $\mathrm{p}<0.001)$. In COPD subjects with low baseline physical activity, no differences were found in survival between unchanged or increased physical activity at follow-up. In addition, subjects without COPD with low physical activity at follow-up had the highest hazard ratio of mortality, irrespective of baseline physical activity level $(\mathrm{p} \leqslant 0.05)$

A decline to low physical activity at follow-up was associated with an increased mortality risk in subjects with and without COPD. These observational data suggest that it is important to assess and encourage physical activity in the earliest stages of COPD in order to maintain a physical activity level that is as high as possible, as this is associated with better prognosis.

0 @ERSpublications Longitudinal decline to a low physical activity level in COPD is associated with a higher all-cause mortality risk http://ow.ly/yTDp8

For editorial comments see page 1107.

This article has supplementary material available from erj.ersjournals.com

Received: Feb 042014 | Accepted after revision: June 182014 | First published online: July 252014

Support statement: This work was supported by Stichting de Weijerhorst (Maastricht, the Netherlands) and Point-One funding from Agentschap NL (Dutch Ministry of Economic affairs, The Hague, the Netherlands). The funders had no role in the study design, data collection and analysis, decision to publish, or preparation of the manuscript. The Copenhagen City Heart Study was supported by grants from the Danish Heart Foundation, the Danish Lung Association and the Danish Medical Research Council.

Conflict of interest: Disclosures can be found alongside the online version of this article at erj.ersjournals.com 


\section{Introduction}

Subjects with chronic obstructive pulmonary disease (COPD) have lower levels of regular physical activity compared to subjects without COPD, even in mild-to-moderate COPD [1]. Many subjects with COPD are not able to meet the recommended minimal amount of regular daily physical activity [2-4]. This may differ between geographic areas, cultural backgrounds and/or methods used to assess daily physical activity [5].

Lower levels of physical activity have been associated with accelerated lung function decline [6], exercise intolerance [1], lower limb muscle weakness [1], lower muscle mass [7] and hospitalisations [8, 9]. In addition, subjects with COPD with very low levels of regular physical activity have the worst prognosis. This has been shown in a population-based study using self-reported levels of physical activity [8], as well as in clinical samples of subjects with COPD using objectified levels of physical activity [10].

In most COPD studies, physical activity has only been assessed at one time point $[6,8,10-13]$. However, subjects with COPD may change their physical activity behaviour over time. Only a few studies have focused on long-term changes in regular physical activity in subjects with COPD, showing a decline in physical activity in $19-26 \%$ of the subjects [14-16]. However, a common limitation to all previous studies is a lack of comparison between physical activity changes in subjects with COPD and subjects without COPD. Therefore, it is not possible to establish whether the observed changes are due to COPD progression or ageing.

A decline in regular physical activity may affect clinical characteristics in subjects with COPD. EsTEBAN et al. [14] showed that a decline in self-reported regular physical activity at 5-year follow-up was associated with a decline in disease-specific health status in subjects with COPD. Moreover, a study in the general population found that maintaining or adopting a moderate or high level of physical activity was associated with lower risk of death [17]. Whether and to what extent changes in regular physical activity affect survival of subjects with COPD remains unknown. Nevertheless, it seems reasonable to hypothesise that a decline in regular physical activity over time may affect risk for all-cause mortality in subjects with COPD.

Therefore we sought to: 1) compare the longitudinal changes in the level of self-reported regular physical activity between subjects with and without COPD; 2) identify baseline determinants of changes in physical activity in subjects with and without COPD; and 3) identify the association between the changes in the level of self-reported regular physical activity and all-cause mortality in subjects with and without COPD.

\section{Methods}

\section{Study design and population}

All subjects participated in the Copenhagen City Heart Study (CCHS) [18]. A sample of the general population aged $\geqslant 20$ years were selected at random and invited to participate. 14223 subjects attended the first CCHS examination in 1976-1978. Participants were re-examined in 1981-1983 (examination 2), 19911994 (examination 3) and 2001-2003 (examination 4), and new 20-49-year-old subjects were invited in an attempt to have a study population with representatives from all age groups. The institutional review board and Danish regional ethics committees approved the research protocol. All participants gave written informed consent [18].

Subjects with at least two consecutive examinations were analysed. COPD was defined as a forced expiratory volume in $1 \mathrm{~s}(\mathrm{FEV} 1) /$ forced vital capacity ratio of $\leqslant 70 \%$ [8]. The date of participation in the examination when COPD was first diagnosed was considered the baseline examination.

After excluding subjects with missing data (lung function and/or physical activity at baseline and/or followup), and/or with an inconsistent diagnosis of COPD, a total of 10004 subjects were analysed; 1270 subjects with COPD and 8734 subjects without COPD. A total of 5408 subjects had one follow-up examination, 2537 subjects had two follow-up examinations, and 2059 subjects had three follow-up examinations. This resulted in 16659 data points with repeated examinations; 1733 in subjects with COPD and 14926 in subjects without COPD (fig. 1). The median (interquartile range; IQR) time between the baseline examination and follow-up examination was 9 (5-11) years.

Mortality data were available in 1166 subjects with COPD and 7143 subjects without COPD. Follow-up started at the last evaluation for each subject, and had a median (IQR) duration of 17.1 (9.3-24.2) years. Thus, there was no artificial period with no mortality.

\section{Measurements}

Physical activity

Physical activity was measured at each examination using a valid and reliable questionnaire [19-21], and was classified into "low", "moderate" or "high", as described elsewhere [17, 20]. For full details refer to the supplementary material. 


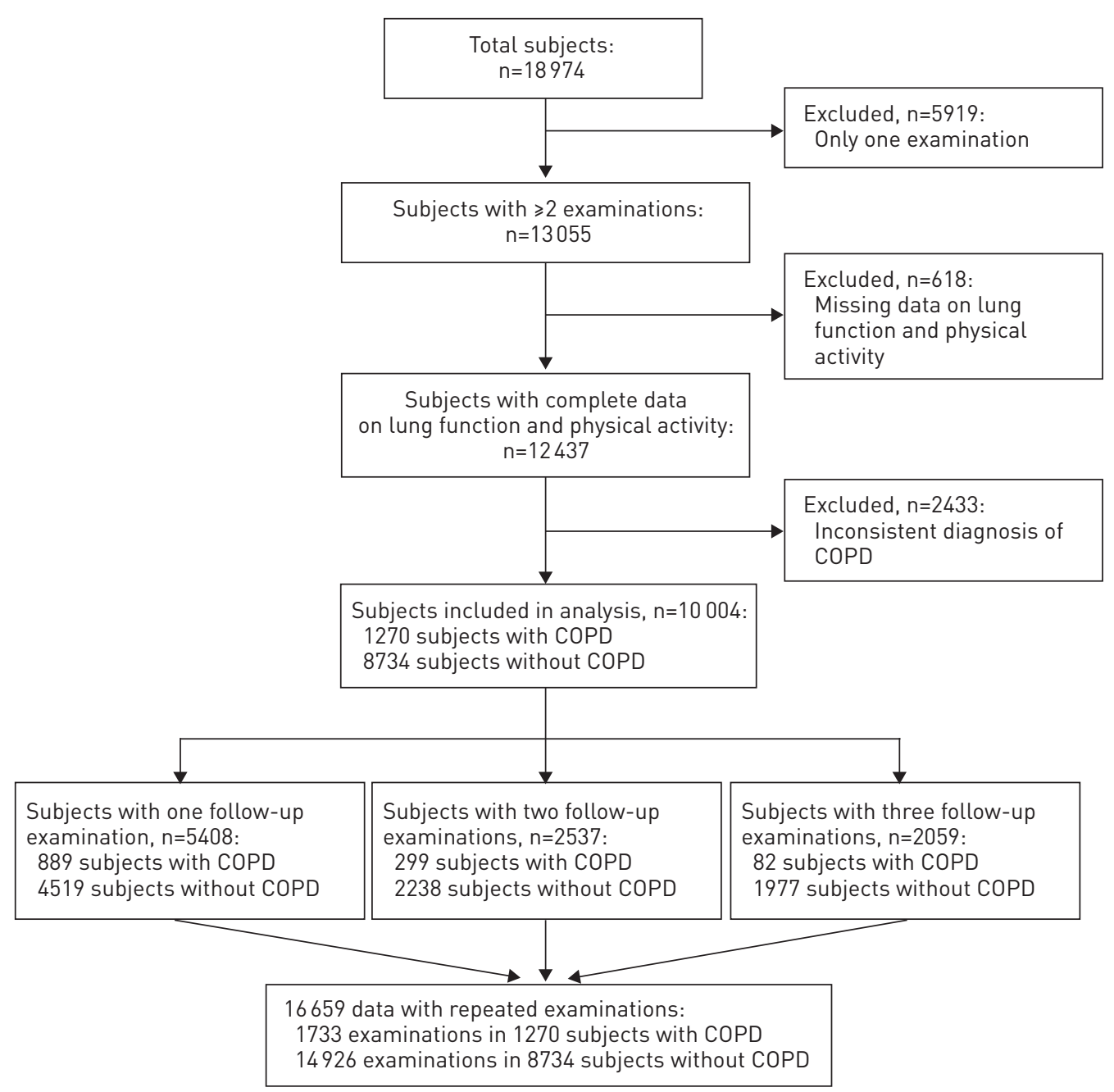

FIGURE 1 Flow chart of study subjects. COPD: chronic obstructive pulmonary disease.

\section{Lung function}

Spirometry was used to assess lung function. At each examination three sets of values were obtained, and at least two measurements differing by $<5 \%$ had to be produced. The highest values of FEV1 and forced vital capacity were used for further analyses. For full details refer to the supplementary material.

\section{Other variables}

Each examination included a clinical examination and a self-administered questionnaire, which included questions regarding: socioeconomic factors (sex, age, education, marital status and cohabitation); current smoking; and self-reported comorbidities (cardiac comorbidities, diabetes and current symptoms of chest pain and/or leg pain).

\section{Statistics}

Differences between subjects with and without COPD were compared using two-tailed t-tests and Chisquared tests as appropriate. Changes in physical activity level from baseline to follow-up examination were stratified according to baseline physical activity level (e.g. low, moderate or high). Differences between physical activity levels and changes in physical activity level were compared using ANOVA and Bonferroni post hoc comparisons or Chi-squared analysis. Generalised estimating equations with exchangeable correlation structure, adjusted for sex and age, were used to identify determinants of longitudinal changes in physical activity level in subjects with and without COPD. Models were stratified according to baseline physical activity level. The outcome variable had the following categories: 1) decrease in physical activity level; 2) no change in physical activity level; or 3) increase in physical activity level. No change in physical activity level was used as the reference category. Possible predictor variables, including sociodemographic data (marital status, cohabitation, and years of education), clinical data (lung function and body mass index (BMI)), 
self-reported comorbidities and smoking history, with a significant association with the outcome variable, were subsequently modelled as possible explanatory variables, as well as the interaction of each variable with time. Results are presented as odds ratios and $95 \%$ confidence intervals.

Cox proportional hazard regression was used to determine the potential effect of longitudinal changes in physical activity as a predictor of survival. The models were stratified according to baseline physical activity level and COPD status (subjects with or without COPD). The exposure variable had the following categories: 1) decrease in physical activity level; 2) no change in physical activity level; and 3) increase in physical activity level. No change in physical activity level was considered as the reference category. Variables considered as potential confounders were tested, and were maintained in the final multivariate models if they modified the hazard ratio estimate for any of the remaining covariates $(\geqslant 10 \%$ change in $\beta$ coefficients). We tested proportionality assumptions and goodness of fit of the models using both the graphical check based on the log-minus-log curves and Schoenfeld residuals. Both methods revealed no violation of the proportional hazard assumption. All analyses were carried out using SPSS version 21.0 (IBM, Somers, NY, USA). A priori, a two-sided level of significance was set at $\mathrm{p} \leqslant 0.05$.

\section{Results}

\section{Characteristics at baseline}

Table 1 shows the baseline characteristics of 1270 subjects with COPD and 8734 subjects without COPD. Significant differences were found in sociodemographic and clinical data, presence of self-reported symptoms and comorbidities, and smoking status (table 1). The baseline characteristics stratified by CCHS examination are included in table E1.

\section{Baseline physical activity}

The proportion of subjects with COPD with a low physical activity level was significantly higher compared to the proportion of subjects without COPD (table 1). Subjects with COPD with a low physical activity level had a significantly worse lung function, shorter education, a higher proportion of current smokers, and more smoking years compared to subjects with COPD with a moderate or high baseline physical activity level. Furthermore, significant differences were found for sex and marital status (table 2). Similar results were found in the subjects without COPD. In addition, age, BMI and the presence of self-reported symptoms and comorbidities were significantly different between subjects without COPD with a low, moderate or high baseline physical activity level (table 2). Differences between subjects with COPD with and without self-reported comorbidities are available in the supplementary material, showing that subjects with comorbidities were older, had a higher BMI and more smoking years.

\section{Longitudinal changes in physical activity}

The proportion of the subjects with COPD with a low baseline physical activity who retained low physical activity at follow-up was significantly higher compared to the proportion of subjects without COPD (42.6 versus $31.9 \%, \mathrm{p}<0.001$ ) (fig. 2). Furthermore, the proportion of subjects with COPD with a moderate baseline physical activity level who changed their physical activity level at follow-up was significantly different compared to the proportion of subjects without COPD (decrease in physical activity: $14.9 \%$ versus $11.4 \%, p=0.003$; increase in physical activity: $26.4 \%$ versus $27.8 \%, p=0.045$ ) (fig. 2 ). Finally, the proportion of subjects with COPD with a high physical activity level at baseline who reported a decline in physical activity at follow-up was significantly higher compared to the subjects without COPD (52.6\% versus $46.7 \%$; $\mathrm{p}=0.010$ ) (fig. 2). All differences remained significant after correction for differences in age and sex $(p<0.05)$. Differences in baseline characteristics of physical activity change in subjects with and without COPD are shown in tables E4 and E5.

\section{Determinants of longitudinal changes in physical activity}

In subjects with COPD, a higher baseline FEV1 was associated with a lower risk of decrease in physical activity level (OR 0.507 and 0.553 for subjects with a moderate or high baseline physical activity, respectively; $\mathrm{p}<0.001$ for both) (tables 3 and E6). Moreover, age (inversely), male sex, not smoking and cohabiting were associated with an increase in physical activity in subjects with COPD with a moderate baseline physical activity. Smoking for a longer number of years was associated with a decrease in physical activity level in subjects with high baseline physical activity level (table 3).

In subjects without COPD, low baseline FEV1, active smoking, female sex, older age, short duration of education, presence of comorbidities, being unmarried and overweight or obese were associated with a decrease in physical activity level (tables 3 and E7). In addition, active smoking, male sex, being married and years of education were associated with an increase in physical activity level (table 3 ). 
TABLE 1 Population characteristics at first examination

\begin{tabular}{|c|c|c|c|}
\hline & Subjects with COPD & $\begin{array}{c}\text { Subjects without } \\
\text { COPD }\end{array}$ & p-value \\
\hline Subjects $n$ & 1270 & 8734 & \\
\hline Males & 57.9 & 42.4 & $<0.001$ \\
\hline Age years & $56.2 \pm 9.5$ & $48.5 \pm 12.6$ & $<0.001$ \\
\hline Marital status & & & 0.040 \\
\hline Married/cohabiting & 68.4 & 65.9 & \\
\hline Other & 31.6 & 34.1 & \\
\hline Cohabitation & & & 0.030 \\
\hline Alone & 32.8 & 30.2 & \\
\hline With others & 67.2 & 69.8 & \\
\hline Education years at school & $8.4 \pm 1.9$ & $9.0 \pm 2.2$ & $<0.001$ \\
\hline BMI $\mathrm{kg} \cdot \mathrm{m}^{-2}$ & $24.6 \pm 3.7$ & $25.1 \pm 4.0$ & 0.001 \\
\hline$<20$ & $9 . \overline{2}$ & $6 . \overline{6}$ & 0.002 \\
\hline $20-25$ & 49.3 & 49.0 & \\
\hline$>25$ & 41.5 & 44.3 & \\
\hline FEV1 L & $2.1 \pm 0.8$ & $2.9 \pm 0.9$ & $<0.001$ \\
\hline FEV $1 \%$ predicted & $67.0 \pm 18.2$ & $90.9 \pm 15.4$ & $<0.001$ \\
\hline FEV $1 /$ FVC $\%$ & $63.0 \pm 6.9$ & $83.4 \pm 6.8$ & $<0.001$ \\
\hline \multicolumn{4}{|l|}{ GOLD stage } \\
\hline 1 & 24.3 & & \\
\hline II & 57.4 & & \\
\hline III & 15.9 & & \\
\hline IV & 2.4 & & \\
\hline \multicolumn{4}{|l|}{$\begin{array}{l}\text { Self-reported symptoms and } \\
\text { comorbidities }\end{array}$} \\
\hline Diabetes & 0.6 & 2.4 & $<0.001$ \\
\hline Cardiac comorbidities & 32.4 & 26.5 & $<0.001$ \\
\hline Chest pain & 38.1 & 33.5 & 0.001 \\
\hline Leg pain while walking & 11.9 & 10.1 & 0.046 \\
\hline \multicolumn{4}{|l|}{ Smoking } \\
\hline Current smoker & 79.1 & 54.8 & $<0.001$ \\
\hline Never-smoker & 5.8 & 26.3 & $<0.001$ \\
\hline Ex-smoker & 15.1 & 18.9 & $<0.001$ \\
\hline Smoking years & $34.5 \pm 11.5$ & $24.6 \pm 12.8$ & $<0.001$ \\
\hline $\begin{array}{l}\text { Self-reported baseline physical } \\
\text { activity level }\end{array}$ & & & $<0.001$ \\
\hline Low & 19.5 & 14.6 & \\
\hline Moderate & 51.5 & 53.8 & \\
\hline High & 29.0 & 31.7 & \\
\hline
\end{tabular}

Data are presented as $\%$ or mean $\pm S D$, unless otherwise stated. The first examination may be different for each subject (Copenhagen City Heart Study examination 1, 2 or 3). COPD: chronic obstructive pulmonary disease; BMI: body mass index; FEV1: forced expiratory volume in 1 s; FVC: forced vital capacity; GOLD: Global Initiative for Chronic Obstructive Lung Disease.

Longitudinal changes in physical activity and all-cause mortality

During a median (IQR) follow-up of 17.1 (9.3-24.2) years, $5392(64.9 \%)$ subjects died. The highest proportion of nonsurvivors was found among subjects with COPD $(n=944 ; 81.0 \%)$. In subjects with COPD and a low physical activity at baseline, no significant differences were found in crude and adjusted hazard ratios of mortality between subjects who remained at low physical active at follow-up and subjects who reported an increase in physical activity (table 4 and fig. 3a). Subjects with COPD and moderate to high physical activity at baseline who reported a low physical activity level at follow-up had the highest crude and adjusted hazard ratios of mortality (1.64 and 1.73, respectively, for subjects with moderate baseline physical activity, and 3.31 and 2.35, respectively, for subjects with high baseline physical activity, both $\mathrm{p}<0.001$ ) (table 4 and figs $3 \mathrm{~b}$ and c). In addition, subjects without COPD with a low physical activity at followup had the highest hazard ratio of mortality, irrespective of baseline physical activity level $(\mathrm{p}<0.05)$ (table 4 and figs $3 \mathrm{~d}-\mathrm{f}$ ). 
TABLE 2 Population characteristics at first examination stratified for baseline physical activity level

Subjects with COPD\#

\begin{tabular}{|c|c|c|c|c|c|c|c|c|}
\hline & & & & & & & & \\
\hline & Low & Moderate & High & p-value & Low & Moderate & High & $\mathrm{p}$-value \\
\hline Subjects $n$ & 248 & 654 & 368 & & 1274 & 4697 & 2763 & \\
\hline Males & 58.9 & 53.8 & 64.4 & 0.004 & 42.4 & 37.4 & 51.0 & $<0.001$ \\
\hline Marital status & & & & 0.025 & & & & 0.025 \\
\hline Married/cohabiting & 61.3 & 69.7 & 70.9 & & 61.3 & 69.7 & 70.9 & \\
\hline Other & 38.7 & 30.3 & 29.1 & & 38.7 & 30.3 & 29.1 & \\
\hline With others & 65.7 & 68.5 & 65.8 & & 68.7 & 71.1 & 68.1 & \\
\hline Education years at school & $8.0 \pm 1.8$ & $8.3 \pm 1.9 *$ & $8.7 \pm 2.1^{*,+}$ & $<0.001$ & $8.4 \pm 2.0$ & $9.0 \pm 2.1^{*}$ & $9.4 \pm 2.3^{*,+}$ & $<0.001$ \\
\hline BMI $\mathrm{kg} \cdot \mathrm{m}^{-2}$ & $24.8 \pm 3.9$ & $24.7 \pm 3.8$ & $24.4 \pm 3.4$ & 0.400 & $26.0 \pm 4.6$ & $25.1 \pm 4.0^{*}$ & $24.6 \pm 3.7^{*,+}$ & $<0.001$ \\
\hline$<20$ & $8 . \overline{5}$ & $8 . \overline{9}$ & 10.3 & 0.878 & $5 . \overline{8}$ & 6.7 & 6.8 & $<0.001$ \\
\hline $20-25$ & 49.2 & 48.9 & 50.0 & & 39.8 & 48.7 & 53.8 & \\
\hline$>25$ & 42.3 & 42.2 & 39.7 & & 54.4 & 44.5 & 39.4 & \\
\hline I & 18.5 & 23.2 & 30.2 & & & & & \\
\hline ॥ & 54.8 & 58.6 & 57.1 & & & & & \\
\hline III & 22.6 & 15.9 & 11.4 & & & & & \\
\hline IV & 4.0 & 2.3 & 1.4 & & & & & \\
\hline \multicolumn{9}{|l|}{$\begin{array}{l}\text { Self-reported symptoms } \\
\text { and comorbidities }\end{array}$} \\
\hline Diabetes & 1.2 & 0.3 & 0.8 & 0.268 & 3.8 & 2.3 & 1.9 & 0.001 \\
\hline Cardiac comorbidities & 32.7 & 34.1 & 29.1 & 0.256 & 33.0 & 26.8 & 22.9 & $<0.001$ \\
\hline Chest pain & 41.9 & 36.7 & 37.9 & 0.403 & 38.5 & 32.9 & 32.3 & 0.001 \\
\hline Leg pain & 15.3 & 12.7 & 8.2 & 0.005 & 17.6 & 9.7 & 7.2 & $<0.001$ \\
\hline Smokers & 84.3 & 79.2 & 75.3 & 0.007 & 62.1 & 55.3 & 50.6 & $<0.001$ \\
\hline Smoking years & $36.5 \pm 10.4$ & $34.1 \pm 11.6^{*}$ & $33.8 \pm 12.0 *$ & 0.010 & $26.7 \pm 12.3$ & $24.9 \pm 12.7^{*}$ & $22.9 \pm 12.8^{*,+}$ & $<0.001$ \\
\hline
\end{tabular}

Data are presented as $\%$ or mean $\pm S D$, unless otherwise stated. The first examination may be different for each subject (Copenhagen City Heart Study examination 1, 2 or 3). COPD: chronic obstructive pulmonary disease; BMI: body mass index; FEV1: forced expiratory volume in 1 s; FVC: forced vital capacity; GOLD: Global Initiative for Chronic Obstructive Lung Disease. \#: $n=1270 ;{ }^{\uparrow}: n=8734 ;{ }^{*}$ : $p<0.05$ versus low physical activity level; ${ }^{+}: p<0.05$ versus moderate physical activity level.

Physical activity level at follow-up: $\square$ Low $\square$ Moderate $\square$ High
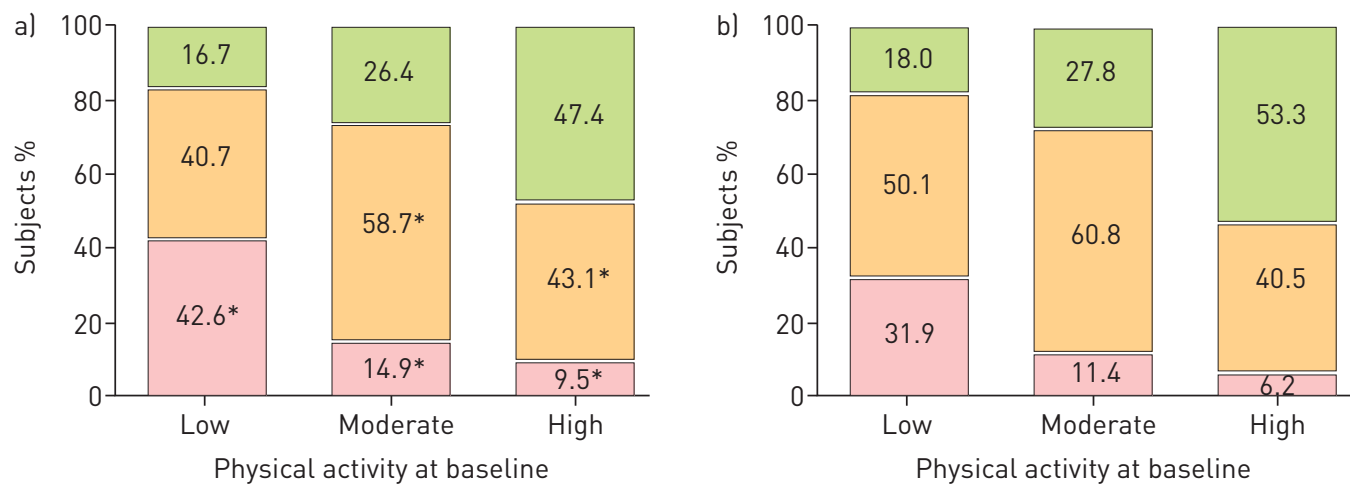

FIGURE 2 Longitudingal changes in physical activity in a) 1733 subjects with chronic obstructive pulmonary disease (COPD) (low: $\mathrm{n}=305$; medium: $\mathrm{n}=890$; high: $\mathrm{n}=538$ ) and b) 14926 subjects without COPD (low: $\mathrm{n}=1914$; medium: $\mathrm{n}=7992$; high: $\mathrm{n}=5020){ }^{\star}: \mathrm{p}<0.05$ compared with subjects without COPD with the same physical activity level. 
TABLE 3 Odds ratios for determinants of longitudinal changes in physical activity in subjects with and without chronic obstructive pulmonary disease (COPD) ${ }^{\#}$

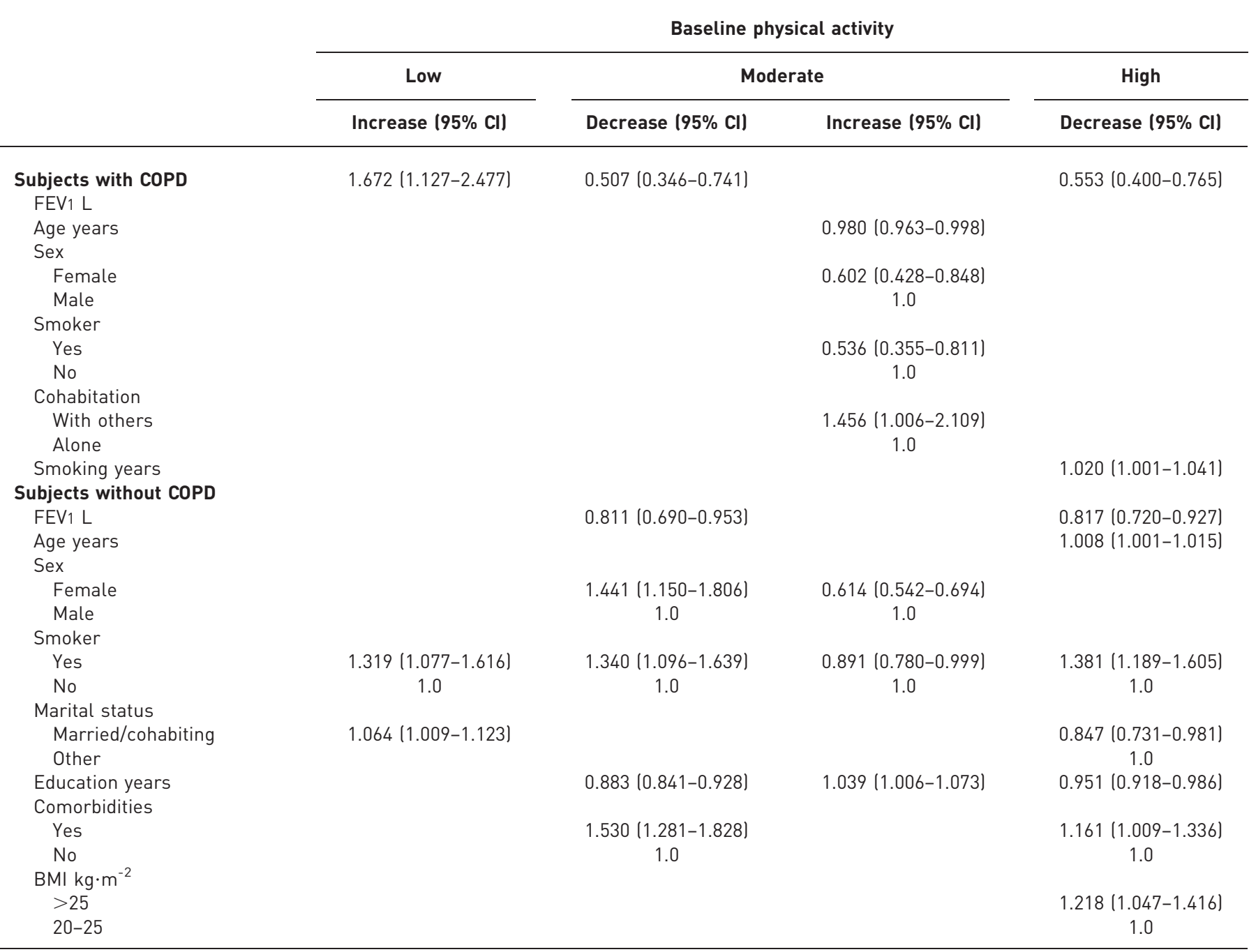

FEV1: forced expiratory volume in $1 \mathrm{~s}$; BMI: body mass index. ${ }^{\#}$ : adjusted for age and sex. The complete models are included in tables E4 and E5.

\section{Discussion}

This study has three major findings: 1) a decline in self-reported regular physical activity is significantly more common in subjects with COPD compared to subjects without COPD; 2) baseline determinants of longitudinal changes in self-reported physical activity are different between subjects with and without COPD; and 3) a decline in physical activity at follow-up was associated with an increased all-cause mortality risk in subjects with and without COPD. Thus, it seems that whereas an increase in physical activity was associated with reduced mortality in subjects without COPD, this was not the case in subjects with COPD who increased their activity level from low to either moderate or high.

The proportion of subjects with COPD with a low physical activity level was significantly higher compared to subjects without COPD, indicating a more inactive lifestyle in subjects with COPD. This finding is consistent with earlier studies $[3,11,22-24]$. The proportions of subjects with COPD with a high physical activity level (29\%) may be somewhat surprising compared to subjects without COPD (31.7\%). Then again, the CCHS cohort is a sample of the general population. This may explain, at least in part, that the proportion of COPD patients with high baseline physical activity level is comparable with the proportion of subjects without COPD who report a high baseline physical activity level. Indeed, COPD patients with Global Initiative for Chronic Obstructive Disease stage I and II were highly prevalent. 
TABLE 4 Crude and adjusted associations between longitudinal changes in physical activity and all-cause mortality in subjects with and without chronic obstructive pulmonary disease (COPD)

Physical activity level

Crude HR $(95 \% \mathrm{Cl})$

p-value

Adjusted HR $(95 \% \mathrm{CI})^{\#}$

p-value

Baseline $\quad$ Follow-up

\section{Subjects with COPD}

$\begin{array}{cc}\text { Low }(n=235) & \text { Low }(n=95) \\ & \text { Moderate }(n=99) \\ & \text { High }(n=41) \\ \text { Moderate }(n=602) & \text { Low }(n=84) \\ & \text { Moderate }(n=351) \\ & \text { High }(n=167) \\ \text { High }(n=329) & \text { Low }(n=34) \\ & \text { Moderate }(n=148) \\ & \text { High }(n=147)\end{array}$

Subjects without COPD
Low $(n=390)$

High $(n=214)$

Low $(n=520)$

Moderate $(n=2342)$

High $(n=520)$

Low $(n=148)$

Moderate $(n=742)$

High $(n=1130)$
Moderate $(n=512)$

\begin{tabular}{cccc}
1 & & 1 & \\
$0.798(0.590-1.079)$ & 0.142 & $0.835(0.605-1.151)$ & 0.270 \\
$0.853(0.567-1.262)$ & 0.425 & $1.012(0.669-1.531)$ & 0.953 \\
$1.644(1.271-2.126)$ & $<0.001$ & $1.729(1.335-2.239)$ & $<0.001$ \\
1 & & 1 & \\
$1.183(0.962-1.455)$ & 0.112 & $1.174(0.952-1.447)$ & 0.134 \\
$3.307(2.202-4.966)$ & $<0.001$ & $2.351(1.516-3.646)$ & $<0.001$ \\
$1.253(0.957-1.639)$ & 0.101 & $1.048(0.790-1.390)$ & 0.746 \\
1 & & 1 & \\
1 & & 1 & \\
1 & & $0.707(0.592-0.844)$ & $<0.001$ \\
$0.745(0.636-0.874)$ & $<0.001$ & $0.747(0.599-0.931)$ & 0.009 \\
$0.777(0.637-0.949)$ & 0.013 & 1 & 0.001 \\
$1.518(1.355-1.700)$ & $<0.001$ & $1.224(1.091-1.373)$ & \\
1 & & 1 & 0.727 \\
$1.120(1.024-1.225)$ & 0.013 & $0.961(0.878-1.053)$ & 0.050 \\
$1.642(1.302-2.070)$ & $<0.001$ & $1.256(1.000-1.590)$ & \\
$1.071(0.932-1.230)$ & 0.331 & $1.007(0.876-1.159)$ & 0.919 \\
1 & & 1 & \\
\hline
\end{tabular}

HR: hazard ratio. " : multivariate model adjusted for sex, age and confounders of the association between physical activity and all-cause mortality, including self-reported comorbidities, smoking, smoking years, education, forced expiratory volume in $1 \mathrm{~s}$ and body mass index. The complete models with all covariates are included in tables E8 and E9.

In addition, the proportion of subjects with COPD with a decline in physical activity was higher compared to the proportion of subjects without COPD, irrespective of physical activity level at baseline (tables 3 and 4). This finding is novel as previous studies on the long-term changes in physical activity did not include a non-COPD control group [14-16].

From cross-sectional studies it is well known that physical activity is associated with clinical, sociodemographic and behavioural factors $[1,5,11,14,22,23,25,26]$. However, data on determinants of longitudinal changes in regular physical activity are limited. The current results indicate that determinants of longitudinal changes in self-reported physical activity differ between subjects with and without COPD. Changes in physical activity in subjects without COPD are determined by a large variety of factors, including clinical data, sociodemographic data and the presence of comorbidities, whereas in subjects with COPD the variables with the highest likelihood for changes in physical activity are sex, the degree of airflow obstruction and smoking status. This may indicate that subjects with COPD are mainly limited by the consequences of COPD and that other variables have a limited additional impact on changes in physical activity. Then again, possible confounders, such as diet and objectified comorbidities, were not assessed, which may also partly explain the greater decline in physical activity in subjects with COPD. Determination of clinical and demographic correlates of physical activity may be important for identifying subjects at risk of developing an inactive lifestyle, but also for designing a specific and adequate physical activity programme for these subjects.

Previously, using the present population, GARCIA-AYMERICH et al. [8] showed that subjects with COPD and a very low to low baseline physical activity level had a higher mortality risk than subjects with COPD and a moderate to high physical activity level. However, changes in physical activity behaviour were not taken into account. Our analyses are the first to show an association between long-term changes in regular physical activity and all-cause mortality in subjects with COPD. A decline to a low physical activity level was associated with the highest all-cause mortality risk in subjects with and without COPD. Moreover, it seems that being moderately physically active may already have important beneficial consequences in subjects with and without COPD. However, in subjects with COPD with a low physical activity level at baseline, no beneficial effect of increased physical activity at follow-up was seen. This suggests that once subjects with 

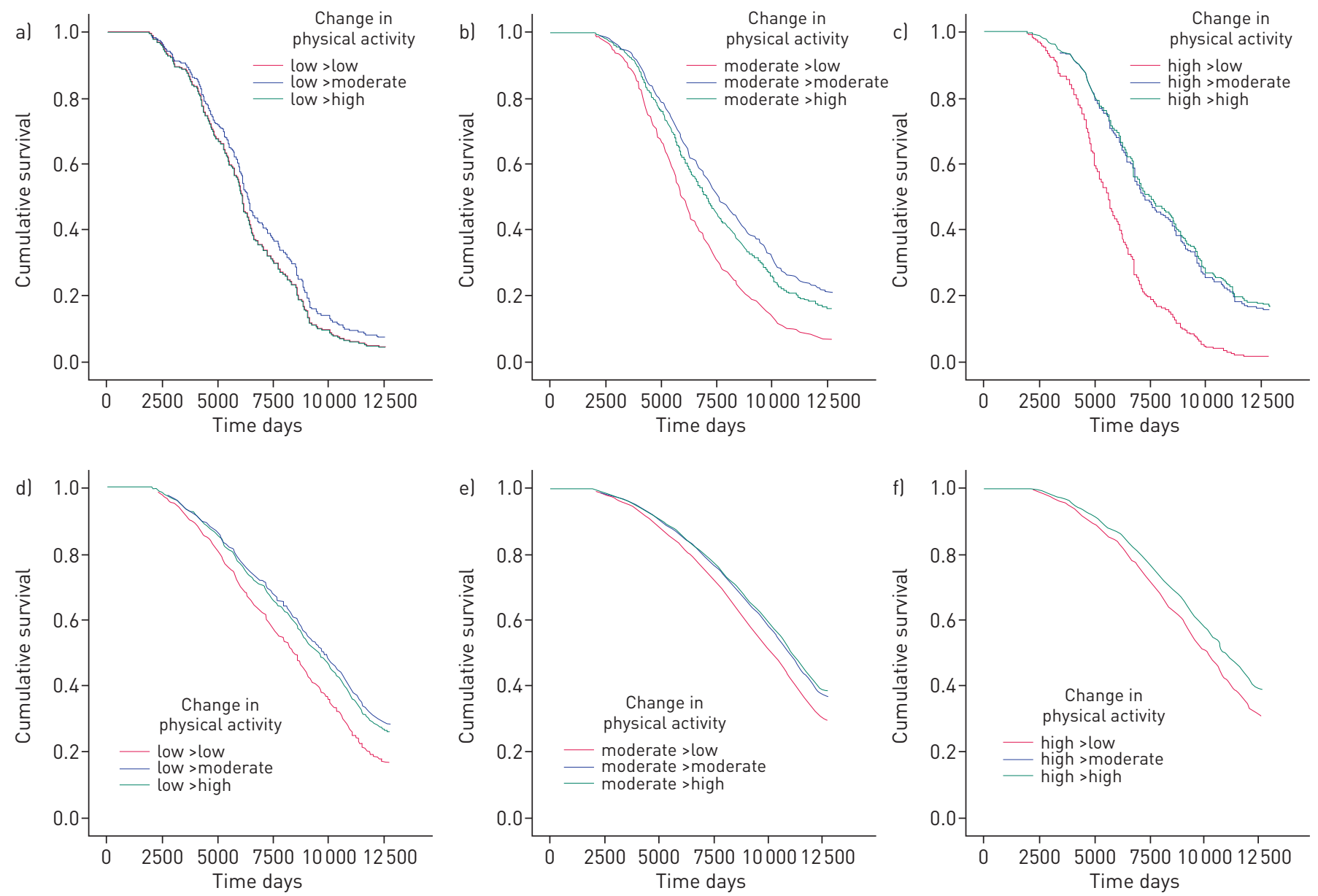

FIGURE 3 Survival curves according to longitudinal changes in physical activity in a-c) subjects with chronic obstructive pulmonary disease (COPD) and d-f) without COPD and a, d) low physical activity level at baseline, b, e) moderate physical activity level at baseline and c, f) high physical activity level at baseline.

COPD become physically inactive, the high mortality risk cannot be reversed by increasing activity levels. Thus, in subjects with COPD it is of clinical importance to remain at a moderate to high physical active level.

Given the association between reduced physical activity and important health-related outcomes [8, 10, 25], as well as the findings of this study, an adequate physical activity level should already be encouraged in subjects with mild COPD. Structured exercise programmes seem to be beneficial in increasing physical activity; however, results are not uniform and long-term data are lacking [27]. Since it is important that subjects with COPD integrate physical activity in their daily life, education and counselling should be an important component of programmes targeting physical activity. Indeed, it has previously been shown that activity monitor-based counselling has a beneficial effect on physical activity and health-related outcomes in patients with chronic diseases [28]. Stimulating physical activity and prevention of a sedentary lifestyle in the earliest stages of COPD may not only result in less adverse health-related consequences and a reduction in healthcare utilisation and costs [8], but also in better survival.

The results of our study may be affected by several limitations. The inclusion of subjects with at least two consecutive examinations may have caused a certain degree of selection bias, as we will have selected the healthiest subjects for analyses. Furthermore, the assessment of physical activity by a questionnaire may represent a subjective level of physical activity. However, it has previously been shown that self-reported measures are fairly accurate of changes in physical activity in large epidemiological studies [29], and it is probably the only way to collect repeated data in such large sample sizes over time. Moreover, the large sample size in this study compensates any degree of nondifferential misclassification of subjects [30]. Finally, the questionnaire used in the CCHS to assess physical activity fulfils the criteria of a patientreported outcome questionnaire [19]. Questions and answer options could easily be interpreted and completed by the participants, subjects' physical activity behaviour was measured without interpretation 
from anyone else, and this questionnaire was able to detect clinically relevant changes in physical activity (fig. 3). As such, it provides important results to subjects with COPD and their healthcare providers in order to make proper, patient-centred treatment decisions, including lifestyle modifications [31].

The used sample is regarded as representative for the Danish population. It might be argued whether our results can be generalised to other populations, for example those who cycle less. With regard to the possibility of residual confounding factors, our results have been adjusted for all available risk factors. It is plausible that other factors not included in the CCHS data (e.g. diet and objectified comorbidities) may also contribute to changes in physical activity. In addition, we did not adjust for changes in FEV1 and BMI, since we believe that these are mediators rather than confounders. Nevertheless, additional analyses showed that the small nonsignificant changes in FEV1 and BMI over time do not contribute significantly to the final multivariate model as presented in tables 4, E8 and E9.

Although a longitudinal study design can limit the effect of reverse causality, it might still be present. However, a previous study showed that earlier reported associations from the CCHS were not due to timedependent confounding [32].

To conclude, our results show that subjects with COPD not only reported a lower physical activity level compared to subjects without COPD, but are also more likely to decrease their level of physical activity over time. Moreover, subjects with a decline to a low physical activity level at follow-up had a higher all-cause mortality risk than subjects who remained or increased regular physical activity compared to baseline. However, the beneficial effect of increasing physical activity did not apply to subjects with COPD who were physically inactive at baseline. Therefore, these observational data suggest that it is important to assess and encourage regular physical activity at the earliest stages of COPD in order to maintain a physical activity level that is as high as possible, as this is associated with a better prognosis.

\section{Acknowledgements}

We would like to thank the staff and participants of the Copenhagen City Heart Study.

\section{References}

1 Waschki B, Spruit MA, Watz H, et al. Physical activity monitoring in COPD: compliance and associations with clinical characteristics in a multicenter study. Respir Med 2012; 106: 522-530.

2 Nelson ME, Rejeski WJ, Blair SN, et al. Physical activity and public health in older adults: recommendation from the American College of Sports Medicine and the American Heart Association. Med Sci Sports Exerc 2007; 39: $1435-1445$.

3 Hernandes NA, Teixeira Dde C, Probst VS, et al. [Profile of the level of physical activity in the daily lives of patients with COPD in Brazil]. J Bras Pneumol 2009; 35: 949-956.

4 Pitta F, Troosters T, Probst VS, et al. [Potential consequences for stable chronic obstructive pulmonary disease patients who do not get the recommended minimum daily amount of physical activity]. J Bras Pneumol 2006; 32: 301-308.

5 Donaire-Gonzalez D, Gimeno-Santos E, Balcells E, et al. Physical activity in COPD patients: patterns and bouts. Eur Respir J 2013; 42: 993-1002.

6 Garcia-Aymerich J, Lange P, Benet M, et al. Regular physical activity modifies smoking-related lung function decline and reduces risk of chronic obstructive pulmonary disease: a population-based cohort study. Am J Respir Crit Care Med 2007; 175: 458-463.

7 Shrikrishna D, Patel M, Tanner RJ, et al. Quadriceps wasting and physical inactivity in patients with COPD. Eur Respir J 2012; 40: 1115-1122.

8 Garcia-Aymerich J, Lange P, Benet M, et al. Regular physical activity reduces hospital admission and mortality in chronic obstructive pulmonary disease: a population based cohort study. Thorax 2006; 61: 772-778.

9 Pitta F, Troosters T, Probst VS, et al. Physical activity and hospitalization for exacerbation of COPD. Chest 2006; 129: $536-544$.

10 Waschki B, Kirsten A, Holz O, et al. Physical activity is the strongest predictor of all-cause mortality in patients with COPD: a prospective cohort study. Chest 2011; 140: 331-342.

11 Pitta F, Troosters T, Spruit MA, et al. Characteristics of physical activities in daily life in chronic obstructive pulmonary disease. Am J Respir Crit Care Med 2005; 171: 972-977.

12 Gosker HR, Lencer NH, Franssen FM, et al. Striking similarities in systemic factors contributing to decreased exercise capacity in patients with severe chronic heart failure or COPD. Chest 2003; 123: 1416-1424.

13 Serres I, Gautier V, Varray A, et al. Impaired skeletal muscle endurance related to physical inactivity and altered lung function in COPD patients. Chest 1998; 113: 900-905.

14 Esteban C, Quintana JM, Aburto M, et al. Impact of changes in physical activity on health-related quality of life among patients with COPD. Eur Respir J 2010; 36: 292-300.

15 Agarwal V, Tetenta S, Bautista J, et al. Longitudinal changes in directly measured physical activity in patients with chronic obstructive pulmonary disease: the trajectory of change. J Cardiopulm Rehabil Prev 2012; 32: 292-295.

16 Waschki B, Schaper M, Sack AL, et al. Decrease of physical activity in patients with COPD in the course of the disease. Eur Respir J 2012; 42: Suppl. 56, abstract 3019.

17 Schnohr P, Scharling H, Jensen JS. Changes in leisure-time physical activity and risk of death: an observational study of 7,000 men and women. Am J Epidemiol 2003; 158: 639-644.

18 Schnohr P, Jensen G, Lange P, et al. The Copenhagen City heart study. Eur Heart J 2001; 3: Suppl. H, H1-H83. 

athletes of the same ages. Circulation 1968; 38: 1104-1115.

Schnohr P. Physical activity in leisure time: impact on mortality. Risks and benefits. Dan Med Bull 2009; 56: 40-71. cholesterol, blood pressure and body mass index. A population based study of 332,182 men and women aged 40-42 years. Eur J Epidemiol 2003; 18: 479-485.

22 Watz H, Waschki B, Meyer T, et al. Physical activity in patients with COPD. Eur Respir J 2009; 33: $262-272$.

23 Troosters T, Sciurba F, Battaglia S, et al. Physical inactivity in patients with COPD, a controlled multi-center pilotstudy. Respir Med 2010; 104: 1005-1011.

24 Vorrink SN, Kort HS, Troosters T, et al. Level of daily physical activity in individuals with COPD compared with healthy controls. Respir Res 2011; 12: 33.

25 Garcia-Aymerich J, Serra I, Gomez FP, et al. Physical activity and clinical and functional status in COPD. Chest 2009; 136: 62-70.

26 Bauman AE, Reis RS, Sallis JF, et al. Correlates of physical activity: why are some people physically active and others not? Lancet 2012; 380: 258-271.

27 Cindy Ng LW, Mackney J, Jenkins S, et al. Does exercise training change physical activity in people with COPD? A systematic review and meta-analysis. Chron Respir Dis 2012; 9: 17-26.

28 Vaes AW, Cheung A, Atakhorrami M, et al. Effect of "activity monitor-based" counseling on physical activity and health-related outcomes in patients with chronic diseases: a systematic review and meta-analysis. Ann Med 2013; 45: 397-412.

29 Shephard RJ. Limits to the measurement of habitual physical activity by questionnaires. Br J Sports Med 2003; 37: 197-206.

30 Szklo M, Nieto J, eds. Epidemiology Beyond the Basics. Gaithersburg, Aspen Publisher, Inc., 2000.

31 Frei A, Williams K, Vetsch A, et al. A comprehensive systematic review of the development process of 104 patientreported outcomes (PROs) for physical activity in chronically ill and elderly people. Health Qual Life Outcomes 2011; 9: 116.

32 Garcia-Aymerich J, Lange P, Serra I, et al. Time-dependent confounding in the study of the effects of regular physical activity in chronic obstructive pulmonary disease: an application of the marginal structural model. Ann Epidemiol 2008; 18: 775-783. 